\title{
Statistical optimisation of polyhydroxyalkanoate production in Bacillus endophyticus using sucrose as sole source of carbon
}

\author{
M. Geethu ${ }^{1} \cdot$ H. Raghu Chandrashekar ${ }^{2} \cdot$ M. S. Divyashree ${ }^{1}$ (D)
}

Received: 14 July 2021 / Revised: 4 August 2021 / Accepted: 22 August 2021 / Published online: 22 September 2021

(C) The Author(s) 2021

\begin{abstract}
Microorganisms have been contemplated as a promising source for the inexhaustible synthesis of many novel materials utilizing renewable sources. Among many of such products, polyhydroxyalkanoate (PHA) remains as an essential biodegradable polymer with functions similar to conventional plastics. Bacillus endophyticus is capable of accumulating biopolymer PHA in nutrient limiting conditions with excess of carbon source. Screening and optimizing the parameters for increased PHA production was done statistically. The optimized medium gave a maximum yield of $46.57 \%$ which was in well agreement with the given predicted value provided by response surface methodology model yield of $47.02 \%$. Optimal media conditions when extrapolated in bioreactor gave an even higher production percentage of 49.9. This is the first report highlighting $49 \%$ of polyhydroxybutyrate statistically using sucrose as a source. The main highlight of the study was the use of wild type strain for producing high quality PHA using simple carbon source which can be a starting platform for using this strain for large scale PHA production industrially. FTIR and ${ }^{1}$ HNMR analysis confirmed the polymer produced.
\end{abstract}

Keywords Bacillus endophyticus $\cdot$ Biopolymer $\cdot$ Bioreactor $\cdot$ Polyhydroxyalkanoate (PHA) $\cdot$ Shake flask cultivation

Abbreviations
$\begin{array}{ll}\text { PHA } & \text { Polyhydroxyalkanoate } \\ \text { CCD } & \text { Central composite design } \\ \text { PB } & \text { Plackett-Burman design } \\ \text { RSM } & \text { Response surface methodology } \\ \text { PM } & \text { Production medium }\end{array}$

\section{Introduction}

Worldwide interest to use bio-based polymers has accelerated as an eco-friendly alternative which resembles plastic in their physio-chemical properties to overcome the increased demands in the rapidly developing fields like biomedical

Communicated by Erko Stackebrandt.

M. S. Divyashree

divyashree.ms@manipal.edu

1 Department of Biotechnology, Manipal Institute of Technology, Manipal Academy of Higher Education, Manipal, Udupi, Karnataka 576104, India

2 Department of Pharmaceutical Biotechnology, Manipal College of Pharmaceutical Sciences, Manipal Academy of Higher Education, Manipal, Udupi, Karnataka 576104, India and industrial sector. Total demand for the biodegradable polymers in North America, Western Europe and Asia reached around 85,000 metric tons and the estimated consumption of biodegradable polymers has increased in these years (Akaraonye et al. 2010). Microorganisms are considered as a promising source for the inexhaustible synthesis of many novel materials utilizing renewable sources. Many eco-friendly materials have been produced as reserve molecules under stress which can be used to resolve the putative problems with several industrial applications. Among many of such products, polyhydroxyalkanoates (PHAs) remain as an essential biodegradable polymer with functions similar to conventional plastics (Amache et al. 2013). A sequence of complex stages starting from biomass accumulation, polymer synthesis and extraction of polymer to recovery is associated with PHA production which significantly influences PHA quality (Mohammed et al. 2019). In recent years, an inclination towards efficient wild strain isolation and screening with quality PHA accumulation capable of utilizing unconventional substrates and altered metabolic pathways was explored widely.

PHA accumulation and bioprocess optimization is very significant to ensure the quality and quantity of biopolymer synthesized via wild type strains. Industries mainly relay on strains like Cupriavidus necator and Alcaligenes latus 
due to their high production rate and PHA yield. In strains like Corynebacterium, Nocardia and Rhodococcus are the only wild type strains reported to synthesize commercially important copolymers from simple carbon sources like glucose, which allowed a decrease in the production cost of the polymer (Kaur and Roy 2015). Decreased yield of the polymer significantly contribute to the overall economy of the polymer as less bioconversion require increased substrate availability to uplift the PHA production (Prados and Maicas 2016). This leads to increase in the overall production rate and to avoid this rapid improvement in the economics of PHA production process need to be implemented by incorporating significant process designing and utilization of cheap substrate thereby increasing PHA yield. Optimization of the bacterial requirement for maximal PHA production enabled by incorporating cheap readily available substrates in Gram positive stains has witnessed a trend recently (Chen and Jiang 2018).

PHA production by microorganism mainly depends on the carbon source and other nutrients provided. A strategy can be introduced to induce pressure on PHA producers to convert available carbon source to biopolymer. This condition can be achieved by optimising the ecosystem and by maintaining a feast and famine condition to organism (Aramvash et al. 2015). As conventional method of optimization consumes lot of time and the relative interactions of different parameters cannot be readily studied, statistical experimental design can be employed to avoid the limitations of one factor at a time method (Tripathi et al. 2013; Din et al. 2014). Screening of significantly influencing parameters and analysing the interaction between them enable to depict their combined effect through factorial design followed by response surface methodology (RSM). Statistical methods of optimisation remains an important strategy in achieving optimal PHA concentration before stepping into large scale production in the presence of cheap carbon sources (Kaur and Roy 2015).

This work mainly focuses on providing experimental insight towards hypothesis linking PHA accumulation and the pattern of utilising sucrose as a major carbon source. Statistical optimization of various production parameters during PHA biosynthesis in Bacillus endophyticus, utilizing sucrose as a sole source of carbon was carried out. Plackett-Burman design (PBD) and central composite design (CCD) were predominantly used in optimising and screening the most influencing parameter in increasing PHA production. The correlation of the increase in cell density and PHA production was also evaluated during this study. The novelty of the work lies in the higher accumulation of PHA by wild type B. endophyticus strain by utilising simple carbon source for polymer biosynthesis.

\section{Materials and methods}

\section{Microorganism and culture maintenance}

Bacillus endophyticus, organism of interest was previously isolated and confirmed in the lab and was frequently subcultured on nutrient agar medium (Himedia, Mumbai, India) and stored at $4{ }^{\circ} \mathrm{C}$. Commonly used staining methods were performed to confirm the microorganism. Primary staining methods like gram staining and endospore staining were performed to confirm Bacillus spp.

\section{Screening and optimization of PHA production media components using statistical experimental design}

\section{Plackett-Burman design (PBD)}

PBD are predominantly used to screen the factors in an experiment. It is necessary to optimize the production medium for PHA biosynthesis by B. endophyticus using sucrose as major carbon source. PB design is largely used to detect the main effects economically and helps in estimating the variances of the factors using minimum experiments. $95 \%$ of relative significance level was chosen to carry out the experimental trials with five factors by experiments designed by Minitab 17. High $(+1)$ and Low $(-1)$ level were coded by PBD and real values of the independent variables were represented in Table 1.

Biopolymer production was done in cotton plugged $250 \mathrm{~mL}$ Erlenmeyer flask with $50 \mathrm{~mL}$ working volume of production medium (PM) which was varied based on the composition obtained by Minitab software which included (NH4) ${ }_{2} \mathrm{SO}_{4}, \mathrm{KH}_{2} \mathrm{PO}_{4}, \mathrm{Na}_{2} \mathrm{HPO}_{4} 2 \mathrm{H}_{2} \mathrm{O}, \mathrm{MgSO}_{4} 7 \mathrm{H}_{2} \mathrm{O}$ Sucrose. All the shake flask experiment was carried out in duplicates. The $\mathrm{pH}$ of the PM was maintained at 7 before inoculation. $10 \%$ of the inoculum was added to production medium which was later incubated at $32{ }^{\circ} \mathrm{C}$ for $72 \mathrm{~h}$.

Table 1 Different levels of experimental factors selected for PHA production by Bacillus endophyticus using Plackett-Burman design

\begin{tabular}{lllc}
\hline No & Components (factors) & $\begin{array}{l}\text { Low level (-1) } \\
\text { g/L }\end{array}$ & $\begin{array}{l}\text { High level } \\
(+1) \mathrm{g} / \mathrm{L}\end{array}$ \\
\hline 1 & $\mathrm{Na}_{2} \mathrm{HPO}_{4}$ & 0.5 & 5 \\
2 & $\mathrm{KH}_{2} \mathrm{PO}_{4}$ & 1.5 & 15 \\
3 & $\left(\mathrm{NH}_{4}\right)_{2} \mathrm{SO}_{4}$ & 1.5 & 15 \\
4 & $\mathrm{MgSO}_{4} \cdot 7 \mathrm{H}_{2} \mathrm{O}$ & 0.2 & 2 \\
5 & Sucrose & 20 & 40 \\
\hline
\end{tabular}




\section{Central composite design (CCD)}

Central composite design was carried out for PHA optimisation studies using sucrose as carbon source. Different combinations of three significant variables $\left(\mathrm{Na}_{2} \mathrm{HPO}_{4}, \mathrm{KH}_{2} \mathrm{PO}_{4}\right.$ and sucrose) found to influence PHA production by PBD was used in CCD. CCD with three variables at 5 levels $(-2$, $-1,0,+1,+2)$ with 20 experiments was used to fit the second order polynomial model. The study was performed to understand the influence of these parameters on responses like biomass and PHA production. The variables and levels for CCD were represented in Table 2. The parameters for the study were selected on literature which was used as components for PHA production medium (Mohammed et al. 2019).

\section{Bioreactor studies}

The initiation of PHA synthesis and the maximal production can be represented as time course study in bioreactor. Batch fermentation to evaluate initiation of PHA biosynthesis was studied in a 3 L bioreactor (Bioflo 110-New Brunswick scientific). The optimised basal medium obtained after statistical optimisation was ran in $3 \mathrm{~L}$ bioreactor. The inoculum $\left(10 \%\right.$ for I L of PM) was cultured until $24 \mathrm{~h}$ at $32{ }^{\circ} \mathrm{C}$ with $150 \mathrm{rpm}$ were aseptically transferred to $3 \mathrm{~L}$ of production medium aseptically. Dissolved oxygen and $\mathrm{pH}$ values were pre-set and regulated by corresponding probes attached to bioreactor system. $200 \mathrm{rpm}$ was the agitation rate maintained and addition of $0.1 \mathrm{~N}$ polyethylene glycol was carried out occasionally as antifoaming agent during foaming. Samples $(15 \mathrm{~mL})$ were drawn at regular intervals to study biomass and PHA production rate of B. endophyticus.

\section{Estimation of cell dry mass}

The culture broth was collected and centrifuged at $10,000 \mathrm{rpm}$ (Plastocraft SSR-V/FM) for $10 \mathrm{~min}$ and the supernatant was analyzed for residual sugar by dinitrosalicylic acid method (Miller 1959) through spectrophotometric analysis at $540 \mathrm{~nm}$. The harvested cell pellet was washed with distilled water and then dried at $80{ }^{\circ} \mathrm{C}$ to a constant weight. As it was gram positive strain, the chances of cell

Table 2 Low and high levels for 3 factors screened for PHA yield by B. endophyticus

\begin{tabular}{lllcc}
\hline No & Components (factors) & Units & $\begin{array}{l}\text { Low level } \\
(-1)\end{array}$ & $\begin{array}{l}\text { High } \\
\text { level } \\
(+1)\end{array}$ \\
\hline 1 & $\mathrm{Na}_{2} \mathrm{HPO}_{4}(\mathrm{~g} / \mathrm{L})$ & $\mathrm{g} / \mathrm{L}$ & 1 & 2 \\
2 & $\mathrm{KH}_{2} \mathrm{PO}_{4}(\mathrm{~g} / \mathrm{L})$ & $\mathrm{g} / \mathrm{L}$ & 1 & 2 \\
3 & Sucrose $(\mathrm{g} / \mathrm{L})$ & $\mathrm{g} / \mathrm{L}$ & 20 & 60 \\
\hline
\end{tabular}

wall disruption was found to be negligible even after exposing to temperature as high as $80^{\circ} \mathrm{C}$ (Russell 2003).

\section{Extraction of PHA}

The PHA content of the cells was estimated by subjecting dry cells into hydrolysis for $1 \mathrm{~h}$ using $4 \%$ Sodium hypochlorite solution at $40{ }^{\circ} \mathrm{C}$ (Slepecky and Law 1960) followed with water and acetone wash for the centrifuged hydrolysate the remained residue obtained after wash was dissolved in solvent chloroform. Gravimetric quantification of obtained PHA film was done routinely after each experimental trial (Lakshman and Shamala 2006).

\section{FTIR and ${ }^{1}$ HNMR analysis of PHA}

The PHA film obtained after dissolving in chloroform was pelletized using potassium bromide $(\mathrm{KBr})$. FTIR spectrum was recorded for each pelletized sample in the sample chamber of FTIR spectrophotometer and was exposed to infra-red radiation. The obtained spectrum using Shimadzu $8400 \mathrm{~S}$ was in the spectral range of $4000-400 \mathrm{~cm}^{-1} .5 \mathrm{mg}$ of PHA film was used for ${ }^{1} \mathrm{H}$ NMR and characterized in Bruker Ascend 400 NMR spectrometer at $22^{\circ} \mathrm{C}$.

\section{Results}

\section{Sequential statistical optimisation of production medium}

\section{Plackett-Burman design}

Software driven experimental trial was developed (Table 3) using Minitab 17 and experiments were carried out sequentially. The main aim of this screening study was to identify the parameters that were highly significant during PHA production. The responses, Biomass and PHA yield was represented in $\mathrm{g} / \mathrm{L}$ and the relative significance of five factors $\left(\mathrm{Na}_{2} \mathrm{HPO}_{4}, \mathrm{KH}_{2} \mathrm{PO}_{4},\left(\mathrm{NH}_{4}\right)_{2} \mathrm{SO}_{4}, \mathrm{MgSO}_{4} \cdot 7 \mathrm{H}_{2} \mathrm{O}\right.$ and concentration of sucrose) at two levels (low and high). The significance level was $95 \%$ and 12 experiments with 3 centre points were carried out in shake flask. The experimental and predicted values of biomass and PHA are represented in Table 3. Statistical analysis of PB design on biomass $(\mathrm{g} / \mathrm{L})$ and PHA production $(\mathrm{g} / \mathrm{L})$ was represented in Tables 4 and 5 respectively as ANOVA table and the effects were represented in Pareto chart for the same in Fig. 1 ( $a$ and $b$ ).

The graphical representation of this phenomenon is given in Pareto chart Fig. 2a, b, which details the relevance of main effect to determine how far these factors are different from zero. The horizontal column in the graph represents the value for $95 \%$ confidence level and gave a $T$ value of 2.18 as 
Table 3 Experimental model of Plackett-Burman design on biomass and PHA yield by B. endophyticus using sucrose as carbon source

\begin{tabular}{|c|c|c|c|c|c|c|c|c|c|}
\hline \multirow[t]{2}{*}{ Run } & \multirow[t]{2}{*}{$\mathrm{Na}_{2} \mathrm{HPO}_{4}(\mathrm{~g} / \mathrm{L})$} & \multirow[t]{2}{*}{$\mathrm{KH}_{2} \mathrm{PO}_{4}(\mathrm{~g} / \mathrm{L})$} & \multirow[t]{2}{*}{$\left(\mathrm{NH}_{4}\right) \mathrm{SO}_{4}$} & \multirow[t]{2}{*}{$\mathrm{MgSO}_{4} \cdot 7 \mathrm{H}_{2} \mathrm{O}$} & \multirow[t]{2}{*}{ Sucrose $\mathrm{g} / \mathrm{L}$} & \multicolumn{2}{|l|}{ Biomass (g/L) } & \multicolumn{2}{|l|}{ PHA (g/L) } \\
\hline & & & & & & Experimental & Predicted & Experimental & Predicted \\
\hline 1 & 5.00 & 1.50 & 15.00 & 0.2 & 20 & 2.130 & 2.21033 & 0.220 & 0.21533 \\
\hline 2 & 5.00 & 15.00 & 1.50 & 2.0 & 20 & 3.028 & 2.98367 & 0.662 & 0.84133 \\
\hline 3 & 0.50 & 15.00 & 15.00 & 0.2 & 40 & 2.558 & 2.31233 & 0.962 & 0.90200 \\
\hline 4 & 5.00 & 1.50 & 15.00 & 2.0 & 20 & 2.206 & 2.06100 & 0.266 & 0.22400 \\
\hline 5 & 5.00 & 15.00 & 1.50 & 2.0 & 40 & 3.894 & 3.83100 & 1.766 & 1.42000 \\
\hline 6 & 5.00 & 15.00 & 15.00 & 0.2 & 40 & 3.900 & 4.01500 & 1.186 & 1.23800 \\
\hline 7 & 0.50 & 15.00 & 15.00 & 2.0 & 20 & 1.200 & 1.31567 & 0.316 & 0.33200 \\
\hline 8 & 0.50 & 1.50 & 15.00 & 2.0 & 40 & 1.126 & 1.20567 & 0.428 & 0.46667 \\
\hline 9 & 0.50 & 1.50 & 1.50 & 2.0 & 40 & 1.114 & 1.17100 & 0.486 & 0.64000 \\
\hline 10 & 5.00 & 1.50 & 1.50 & 0.2 & 40 & 2.966 & 3.02300 & 0.806 & 0.96733 \\
\hline 11 & 0.50 & 15.00 & 1.50 & 0.2 & 20 & 1.308 & 1.43033 & 0.338 & 0.49667 \\
\hline 12 & 0.50 & 1.50 & 1.50 & 0.2 & 20 & 0.602 & 0.47300 & 0.360 & 0.05267 \\
\hline 13 & 2.75 & 8.25 & 8.25 & 1.1 & 30 & 2.858 & 2.90933 & 1.694 & 1.68267 \\
\hline 14 & 2.75 & 8.25 & 8.25 & 1.1 & 30 & 2.940 & 2.90933 & 1.698 & 1.68267 \\
\hline 15 & 2.75 & 8.25 & 8.25 & 1.1 & 30 & 2.930 & 2.90933 & 1.656 & 1.68267 \\
\hline
\end{tabular}

Table 4 Statistical analysis of Plackett-Burman design on biomass yield with five fermentative parameters
Table 5 Statistical analysis of Plackett-Burman design on PHA yield with five fermentative parameters

\begin{tabular}{lccccccc}
\hline Source & $d f$ & Adj SS & Adj MS & $F$ value & $p$ value & Main effect & Std. error \\
\hline Model & 6 & 14.9854 & 2.49756 & 118.35 & 0 & & \\
Linear & 5 & 13.6711 & 2.73422 & 129.57 & 0 & & \\
$\mathrm{Na}_{2} \mathrm{HPO}_{4}$ & 1 & 8.6972 & 8.69722 & 412.14 & 0 & 1.7027 & 0.0419 \\
$\mathrm{KH}_{2} \mathrm{PO}_{4}$ & 1 & 2.7495 & 2.74946 & 130.29 & 0 & 0.9573 & 0.0419 \\
$\left(\mathrm{NH}_{4}\right)_{2} \mathrm{SO}_{4}$ & 1 & 0.0036 & 0.00361 & 0.17 & 0.69 & 0.0347 & 0.0419 \\
$\mathrm{MgSO}_{4} \cdot 7 \mathrm{H}_{2} \mathrm{O}$ & 1 & 0.0669 & 0.0669 & 3.17 & 0.113 & -0.1493 & 0.0419 \\
Sucrose & 1 & 2.1539 & 2.15392 & 102.07 & 0 & 0.8473 & 0.0419 \\
Curvature & 1 & 1.3142 & 1.31424 & 62.28 & 0 & & \\
Error & 8 & 0.1688 & 0.0211 & & & & \\
Lack-of-fit & 6 & 0.1648 & 0.02747 & 13.73 & 0.069 & & \\
Pure error & 2 & 0.004 & 0.002 & & & & \\
Total & 14 & 15.1542 & & & & & \\
\hline
\end{tabular}

$d f$ degrees of freedom, $S S$ sum of squares

$S=0.14526 ; R^{2}=98.89 \% ; R_{(\text {adj.) }}^{2}=98.05 \% ; F=\mathrm{MS}_{(\text {Factor })} / \mathrm{MS}_{\text {(Error) }}$

\begin{tabular}{lcllrlrl}
\hline Source & $d f$ & Adj SS & Adj MS & $F$ value & $p$ value & Main effect & Std. error \\
\hline Model & 6 & 4.58603 & 0.76434 & 18.41 & 0 & & \\
Linear & 5 & 2.02502 & 0.405 & 9.75 & 0.003 & & \\
$\mathrm{Na}_{2} \mathrm{HPO}_{4}$ & 1 & 0.33869 & 0.33869 & 8.16 & 0.021 & 0.3360 & 0.0588 \\
$\mathrm{KH}_{2} \mathrm{PO}_{4}$ & 1 & 0.59141 & 0.59141 & 14.24 & 0.005 & 0.4440 & 0.0588 \\
$\left(\mathrm{NH}_{4}\right)_{2} \mathrm{SO}_{4}$ & 1 & 0.09013 & 0.09013 & 2.17 & 0.179 & -0.1733 & 0.0588 \\
$\mathrm{MgSO}_{4} \cdot 7 \mathrm{H}_{2} \mathrm{O}$ & 1 & 0.00023 & 0.00023 & 0.01 & 0.943 & 0.0087 & 0.0588 \\
Sucrose & 1 & 1.00457 & 1.00457 & 24.19 & 0.001 & 0.5787 & 0.0588 \\
Curvature & 1 & 2.56101 & 2.56101 & 61.68 & 0 & & \\
Error & 8 & 0.33217 & 0.04152 & & & & \\
Lack-of-fit & 6 & 0.33109 & 0.05518 & 102.7 & 0.01 & & \\
Pure error & 2 & 0.00107 & 0.00054 & & & & \\
Total & 14 & 4.9182 & & & & & \\
\hline
\end{tabular}



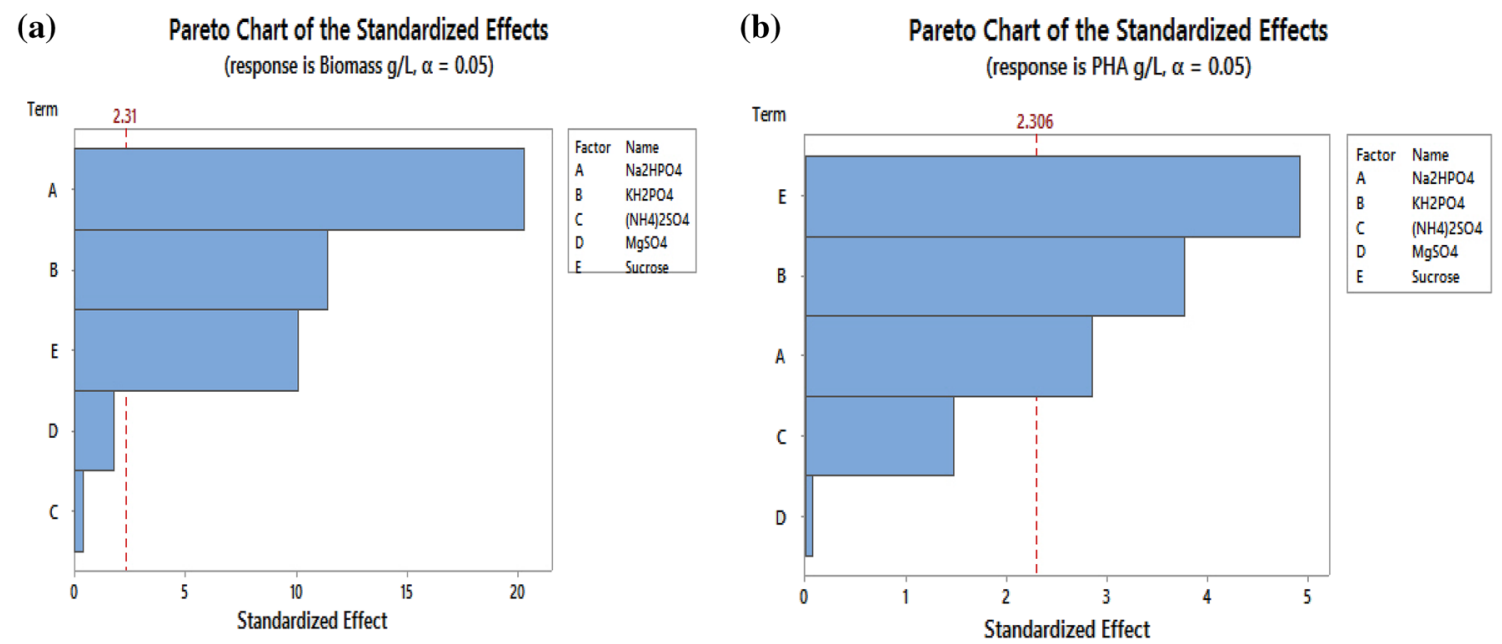

Fig. 1 Standardized effects on the fermentative parameters shown in Pareto chart for a biomass $(\mathrm{g} / \mathrm{L})$ and b PHA (g/L) production by B. endophyticus

Fig. 2 2D contour plot showing the interactive effects of three variables showing the interaction effect of Biomass $\mathrm{g} / \mathrm{L}$ of B.endophyticus using sucrose as carbon source
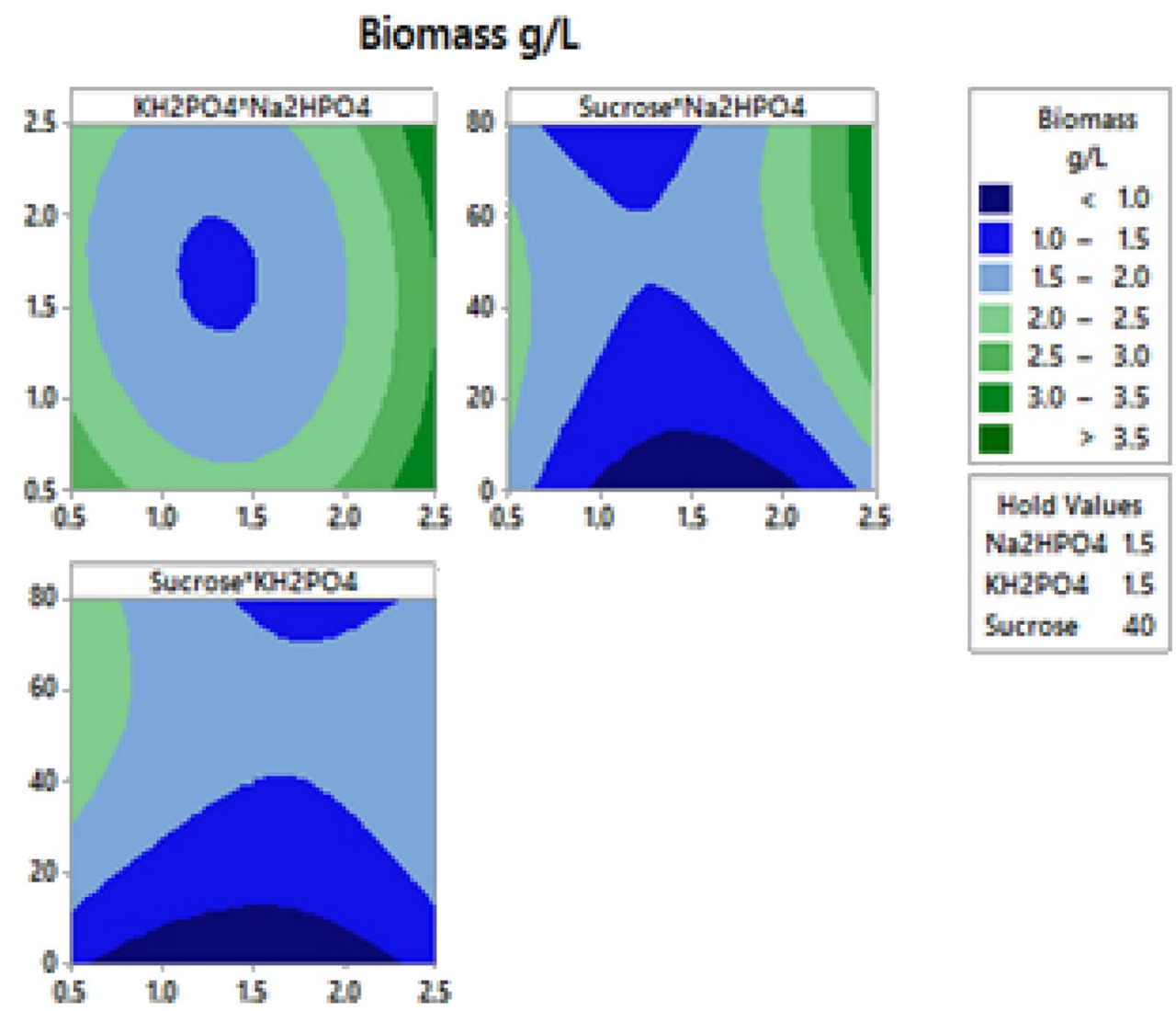

a vertical line in the plot. The $T$ value indicates the minimum statistically significant effect for $95 \%$ significant level. From Pareto chart Fig. 1a, b, it was observed that the concentration of three factors $\left(\mathrm{Na}_{2} \mathrm{HPO}_{4}, \mathrm{KH}_{2} \mathrm{PO}_{4}\right.$ and concentration of sucrose) was positively affecting biomass and PHA yield. Independent variables above $95 \%$ were considered as significantly influencing biomass and PHA yield.
Designing the screening experiment was to evaluate the factors that highly influence PHA production. Before specific screening of the highly influencial parameters on the production, Plackett-Burman studies were carried out which gave an idea on which the production may relay. The factors used for the experiments were selected that had close link with the production during shake flask cultivation done 
prioirly. This was clearly visualised in pareto chart which showed the standardised lineance of the production towards each factors. The cumulative inference is that the concentration of $\mathrm{Na}_{2} \mathrm{HPO}_{4}, \mathrm{KH}_{2} \mathrm{PO}_{4}$ and sucrose influences the overall yield of biomass and PHA production during the course of growth. Sucrose concentration readily had an influence on biomass and the production of biopolymer. During biomass increment, the role of $\mathrm{KH}_{2} \mathrm{PO}_{4}$ and $\mathrm{Na}_{2} \mathrm{HPO}_{4}$ was found to be significant which indicates the trivial role of potassium and sodium ions for different transport system and cytoplasmic signalling (Wang and Bakken 1998; Bora 2013). This enable cells to divide and increase in cell mass. Whereas during PHA production, the role of $\left(\mathrm{NH}_{4}\right)_{2} \mathrm{SO}_{4}$ was found to be insignificant which justifies the correlation of limited nitrogen source for enhancing PHA production.

Regression equation for the Model (Biomass $\mathrm{g} / \mathrm{L}$ ):

$$
\begin{aligned}
\text { Biomass g/L }= & -0.657+0.3784 \mathrm{Na}_{2} \mathrm{HPO}_{4}+0.07091 \mathrm{KH}_{2} \mathrm{PO}_{4} \\
& +0.00257\left(\mathrm{NH}_{4}\right) 2 \mathrm{SO}_{4}-0.0830 \mathrm{MgSO}_{4} \\
& +0.04237 \text { Sucrose }+0.7400 \mathrm{Ct} \mathrm{Pt} .
\end{aligned}
$$

Regression equation for the Model (PHA g/L):

$$
\begin{aligned}
\text { PHA g/L }= & -0.594+0.0747 \mathrm{Na}_{2} \mathrm{HPO}_{4}+0.03289 \mathrm{KH}_{2} \mathrm{PO}_{4} \\
& -0.01284\left(\mathrm{NH}_{4}\right)_{2} \mathrm{SO}_{4}+0.0048 \mathrm{MgSO}_{4} \\
& +0.02893 \text { Sucrose }+1.033 \mathrm{Ct} \mathrm{Pt} .
\end{aligned}
$$

Effect of carbon source, sucrose concentration (0-4\%) on PHA biosynthesis were studied in B. endophyticus in PHA production medium. The correlation of biomass and PHA in the excess presence of sucrose was studied as batch cultivation using statical optimisation tool. The biomass accumulation is very essential, as there is a direct relationship between the biomass and PHA content as PHA is directly accumulated within the cytoplasm. Residual biomass is the catalytic component responsible for the metabolic activity, so increase in the biomass determine the quantity of PHA that was produced potentially. So the cell growth balance is necessary during the growth phase to avoid incomplete PHA accumulation. High biomass \% is directly proportional to PHA concentration so it is necessary to decide the harvesting time to attain maximum PHA production (Pijuan et al. 2009). Commercial production of PHA relay mainly on fed batch and batch cultivation. Taking this into consideration, batch cultivation in shake flask was carried out and the optimal concentration of components obtained via statistical optimisation was extrapolated in bioreactor. It was necessary to carry out RSM which helped in specifically determine the second order behaviour of the parameters (Chen and Jiang 2018). It also enables the correlation between the factors and responses with the best combination of the parameters can be used by the model to obtain maximum yield. Using factorial experimental design, the errors generated gets nullified and the overall effects of variable provides mutual interaction of the parameters through factorial experimental design. The maximum PHB yield was $49.47 \%$ of biomass after $72 \mathrm{~h}$ of cultivation which was not reported by any Bacillus strain so far utilising sucrose as sole carbon source (Mohammed et al. 2019).

\section{Central composite design and response surface methodology}

Central composite design was carried out for PHA optimisation studies using sucrose as carbon source. Different combinations of three significant variables $\left(\mathrm{Na}_{2} \mathrm{HPO}_{4}, \mathrm{KH}_{2} \mathrm{PO}_{4}\right.$ and sucrose) found to influence PHA production by $\mathrm{PBD}$ were used in CCD. CCD with three variables at five levels $(-2,-1,0,+1,+2)$ with 20 experiments was used to fit the second order polynomial model. The study was performed to understand the influence of these parameters on responses like biomass and PHA production. The variables and levels for CCD were represented in Table 6 and the design table obtained by Minitab 17 is represented in Table 7 .

$$
\begin{aligned}
\text { Biomass g/L }= & 4.573-3.541 Z_{1}-1.729 Z_{2}+0.02468 Z_{3} \\
& +1.0907 Z_{1} \times Z_{1}+0.5217 Z_{2} \times Z_{2} \\
& -0.000296 Z_{3} \times Z_{3}+0.140 Z_{1} \times Z_{2} \\
& +0.01140 Z_{1} \times Z_{3}-0.00510 Z_{2} \times Z_{3} .
\end{aligned}
$$

$$
\begin{aligned}
\text { PHA g/L }= & 1.754-1.003 Z_{1}-1.137 Z_{2}+0.01335 Z_{3} \\
& +0.1945 Z_{1} \times Z_{1}+0.1835 Z_{2} \times Z_{2} \\
& -0.000237 Z_{3} \times Z_{3}+0.288 Z_{1} \times Z_{2} \\
& +0.00400 Z_{1} \times Z_{3}+0.00205 Z_{2} \times Z_{3} .
\end{aligned}
$$

where $Z_{1}$ is the concentration of $\mathrm{Na}_{2} \mathrm{HPO}_{4}, Z_{2}$ is the concentration $\mathrm{KH}_{2} \mathrm{PO}_{4} \mathrm{~g} / \mathrm{L}, Z_{3}$ is the concentration of Sucrose.

The linear models of the regression analysis $\left(Z_{1}, Z_{2}\right.$ and $Z_{3}$ ) demonstrated the significance of the parameters relatively. Similarly the quadratic models $Z_{1}^{2}, Z_{2}^{2}$ and $Z_{3}^{2}$ and $Z_{1} Z_{3}$ two way interaction model were found to be significant.

\section{Fit of model}

The design matrix in terms of coded and real values along with the response (Biomass and PHA $\mathrm{g} / \mathrm{L}$ ) is represented in Table 6. The maximum biomass $\mathrm{g} / \mathrm{L}$ obtained was $2.59 \mathrm{~g} / \mathrm{L}$ and maximum PHA g/L was $0.88 \mathrm{~g} / \mathrm{L}$ (Table 6). The competence of the CCD model and the fitness evaluation was performed by ANOVA and the statistical significance of the model was predicted based on the $F$ test and $P$ test for analysis of variance (ANOVA) is given in Tables 7 and 8 . The model $F$ value of 51.75 (Biomass $\mathrm{g} / \mathrm{L}$ in Table 7) and 7.95 (PHA g/L in Table 8) indicates the significance of the model and the lack of fit value of 0.0133 and 0.79 for biomass and 


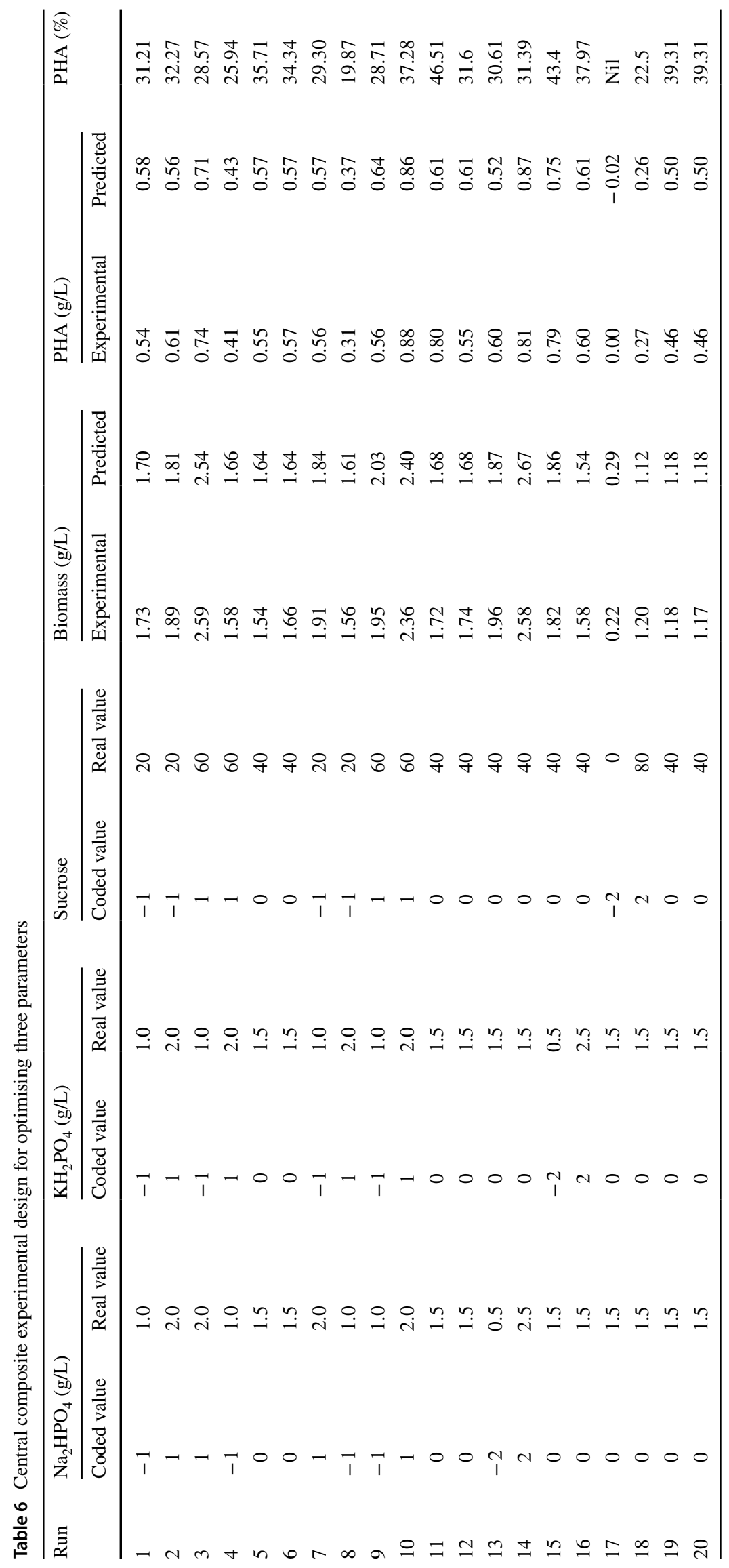


Table 7 Analysis of variance for biomass ( $\mathrm{g} / \mathrm{L}$ ) with three factors

\begin{tabular}{llllll}
\hline Source & $d f$ & Adj SS & Adj MS & $F$ value & $p$ value \\
\hline Model & 11 & 5.23547 & 0.47595 & 51.75 & 0 \\
Blocks & 2 & 1.02819 & 0.5141 & 55.9 & 0 \\
Linear & 3 & 1.42927 & 0.47642 & 51.8 & 0 \\
$\mathrm{Z}_{1}$ & 1 & 0.62885 & 0.62885 & 68.37 & 0 \\
$\mathrm{Z}_{2}$ & 1 & 0.09986 & 0.09986 & 10.86 & 0.011 \\
$\mathrm{Z}_{3}$ & 1 & 0.70057 & 0.70057 & 76.17 & 0 \\
Square & 3 & 2.93903 & 0.97968 & 106.52 & 0 \\
$\mathrm{Z}_{1}^{2}$ & 1 & 1.78433 & 1.78433 & 194.01 & 0 \\
$\mathrm{Z}_{2}^{2}$ & 1 & 0.4082 & 0.4082 & 44.38 & 0 \\
$\mathrm{Z}_{3}^{2}$ & 1 & 0.33607 & 0.33607 & 36.54 & 0 \\
$2-$ Way interaction & 3 & 0.13458 & 0.04486 & 4.88 & 0.033 \\
$\mathrm{Z}_{1} \mathrm{Z}_{2}$ & 1 & 0.0098 & 0.0098 & 1.07 & 0.332 \\
$\mathrm{Z}_{1} \mathrm{Z}_{3}$ & 1 & 0.10397 & 0.10397 & 11.3 & 0.01 \\
$\mathrm{Z}_{2} \mathrm{Z}_{3}$ & 1 & 0.02081 & 0.02081 & 2.26 & 0.171 \\
Error & 8 & 0.07358 & 0.0092 & & \\
Lack-of-fit & 5 & 0.06691 & 0.01338 & 6.02 & 0.085 \\
Pure error & 3 & 0.00667 & 0.00222 & & \\
Total & 19 & 5.30905 & & & \\
\hline
\end{tabular}

$d f$ degrees of freedom, $S S$ sum of squares, $M S$ mean square $S=0.0959016 ; R^{2}=98.61 \% ; R_{(\text {adj) }}^{2}=96.71 \% ; F=\mathrm{MS}_{(\text {Factor })} / \mathrm{MS}_{(\text {Error })}$

PHA respectively was found to be less than the $F$ values

Table 8 Analysis of variance for PHA (g/L) with three factors

\begin{tabular}{llllcl}
\hline Source & $d f$ & Adj SS & Adj MS & $F$ value & $p$ value \\
\hline Model & 11 & 0.750316 & 0.068211 & 7.95 & 0.003 \\
Blocks & 2 & 0.041597 & 0.020799 & 2.42 & 0.15 \\
Linear & 3 & 0.216226 & 0.072075 & 8.4 & 0.007 \\
$\mathrm{Z}_{1}$ & 1 & 0.119025 & 0.119025 & 13.87 & 0.006 \\
$\mathrm{Z}_{2}$ & 1 & 0.021025 & 0.021025 & 2.45 & 0.156 \\
$\mathrm{Z}_{3}$ & 1 & 0.076176 & 0.076176 & 8.88 & 0.018 \\
Square & 3 & 0.431045 & 0.143682 & 16.74 & 0.001 \\
$\mathrm{Z}_{1}{ }^{2}$ & 1 & 0.056745 & 0.056745 & 6.61 & 0.033 \\
$\mathrm{Z}_{2}{ }^{2}$ & 1 & 0.050508 & 0.050508 & 5.89 & 0.041 \\
$\mathrm{Z}_{3}{ }^{2}$ & 1 & 0.21603 & 0.21603 & 25.17 & 0.001 \\
2-Way interaction & 3 & 0.057634 & 0.019211 & 2.24 & 0.161 \\
$\mathrm{Z}_{1} \mathrm{Z}_{2}$ & 1 & 0.041472 & 0.041472 & 4.83 & 0.059 \\
$\mathrm{Z}_{1} \mathrm{Z}_{3}$ & 1 & 0.0128 & 0.0128 & 1.49 & 0.257 \\
$\mathrm{Z}_{2} \mathrm{Z}_{3}$ & 1 & 0.003362 & 0.003362 & 0.39 & 0.549 \\
Error & 8 & 0.068657 & 0.008582 & & \\
Lack-of-fit & 5 & 0.039085 & 0.007817 & 0.79 & 0.618 \\
Pure error & 3 & 0.029572 & 0.009857 & & \\
Total & 19 & 0.818973 & & & \\
\hline
\end{tabular}

$d f$ degrees of freedom, $S S$ sum of squares, $M S$ mean square $S=0.0926396 ; R^{2}=91.62 \% ; R_{(\text {adj })}^{2}=80.09 \% ; F=\mathrm{MS}_{(\text {Factor })} / \mathrm{MS}_{(\text {Error })}$ confirming the significance of the model in predicting the overall PHA yield with respect to biomass.

\section{Interaction of variables on responses}

The two dimensional (2D) contour plot are usually used to visually represent the regression equations to study the interaction effect of independent and dependent variable. In these plots, two response factors are presented keeping other factor at constant and the extent of interaction is usually determined by the shape of the plot. To study the interaction effect between three factors that is significantly affecting biomass and PHA accumulation was well studied using 2D plots as represented in Figs. 2 and 3 respectively. The circular contour plot Fig. $2 \mathrm{a}$ between $\mathrm{KH}_{2} \mathrm{PO}_{4}$ and $\mathrm{Na}_{2} \mathrm{HPO}_{4}$ shows that there is only less interaction between these factors in increasing biomass accumulation.

The factorial design enabled to restrict the number of experiment to 15 and gave an idea about the higher order interaction among the factors. All the experiments were conducted in a randomized manner. The synergistic effect of 2 or more factors could be thoroughly analyzed. These significant parameters were taken up for optimization using central composite design. For further confirmation and to obtain the right combination, those factors which showed influence was taken for central composite design and helped in concluding the right combination of parametrs. The coefficient of determination $R^{2}$ value determines fit of the model which was $0.9162(p<0.05), 91.62 \%$ for PHA and 0.9861 $(p<0.05), 98.61 \%$ for biomass production. This enables in identifying the variability of the response which can be predicted. The observed model was relevant in predicting the optimal growth and PHA biosynthesis in B. endophyticus using sucrose as carbon source based on the predicted values given by the statistical CCD model.

The elliptical shape of contour plot as in Fig. 2a indicates a negative effect on PHA production with respect to higher concentration of $\mathrm{KH}_{2} \mathrm{PO}_{4}$ and $\mathrm{Na}_{2} \mathrm{HPO}_{4}$ which decreases PHA production. This was in well agreement with the necessity of nutrient limiting condition for organism to initiate PHA production. In our another study, it was reported that PHA production in the presence of inexpensive carbon source like sugarcane molasses $(4 \%)$ with increased agitation rate enhanced PHA production by $10.7 \mathrm{~g} / \mathrm{L}$ with $15.37 \mathrm{~g} / \mathrm{L}$ of cell mass statistically. This experimental model created using CCD reported that increase in sugar concentration $(>4 \%)$ had a negative influence on biopolymer production (Geethu et al. 2019).

Mohanrasu (2020) reported the importance of nitrogen, potassium and sodium concentration in the basal medium for cell growth for the PHA producers which later on limiting 
Fig. 3 2D contour plot showing the interactive effects of three variables and on PHA production by B.endophyticus using sucrose as carbon source

\section{PHA g/L}
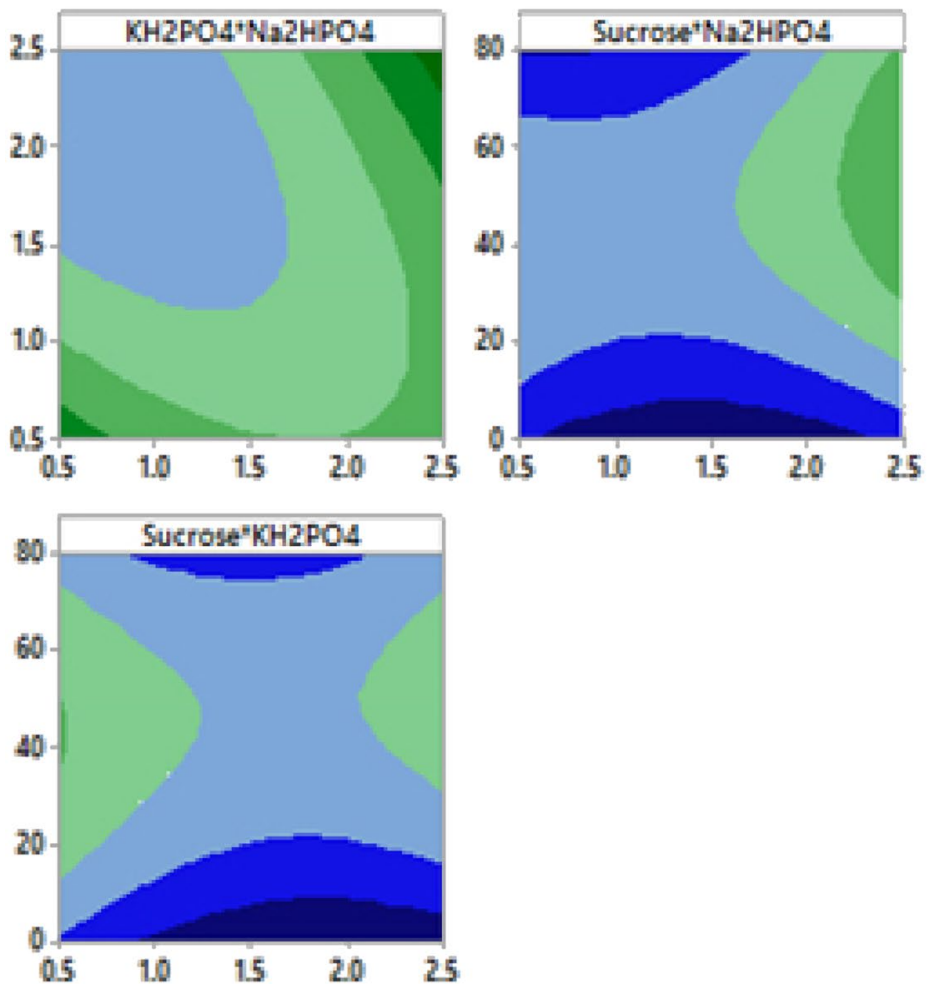

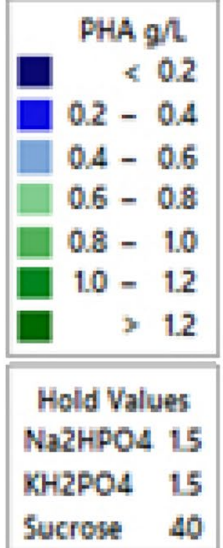

the nutrients enhance the production. $2.74 \mathrm{~g} / \mathrm{L}$ of PHA was reported by the same authors in $B$. megaterium strain utilizing glucose as carbon source (Mohanrasu et al. 2020). Similarly in this study as well, the significance and dependency of the strain on $\mathrm{N}, \mathrm{P}$ and $\mathrm{Na}$ source were clearly shown as a prompt requirement to increase the cell mass. Later for PHA production, limitation of the nitrogen source was found to be significant which shows the limitation of nutrients except carbon enhances PHA production (Narayanan et al. 2021). The conclusive finding of the study is that the basal medium can be enriched with essential nutrients for fast cell growth and later during the late log phase reducing the nitrogen source can amplify PHA production. The insignificant correlation obtained during statistical optimization can be correlated in this case. Similar results were reported by another group where in growth of B. aryabhattai were found to excess in nutrient rich medium given initially with extra nitrogen source which on depletion of the same enhanced PHA production (Pillai et al. 2017). Another study reported that PHB was cell-growth-associated and PHA production started with log phase around $36 \mathrm{~h}$ and increase to maximum around $48 \mathrm{~h}$ with minimal nitrogen sources (Yao et al. 2012).

\section{Bioreactor studies for the optimised medium}

PHA production in the excess presence of sucrose by $B$. endopyticus was further scaled up in $3 \mathrm{~L}$ bioreactor (New Brunswick Scientific, Bioflo 110) using optimal media components suggested by statistical model. A working volume of $1 \mathrm{~L}$ of production media with optimal concentration of $\mathrm{KH}_{2} \mathrm{PO}_{4}, \mathrm{Na}_{2} \mathrm{HPO}_{4}$ and sucrose with $1.5,1.5 \mathrm{~g} / \mathrm{L}$ and $4 \%$ was used respectively for batch cultivation. As per statistical analysis (CCD) the obtained PHA \% obtained using this optimal condition was 46.5 (11th run Table 6). $250 \mathrm{rpm}$ agitation rate with the desired dissolved oxygen of $100 \%$ was maintained during $72 \mathrm{~h}$ of batch cultivation. In this scale up study, it was found that at $72 \mathrm{~h}$ the PHA production was $49.9 \%$ which was even higher than the production obtained during the statistical experimental run. So this optimised media was in well accordance with the suggested model and can be used further for increased production. A similar statistical study was conducted previously under controlled medium condition with initial $4 \%$ sugar content provided by SCM at $250 \mathrm{rpm}$ by test organism which gave upto $68.5 \%$ of PHA. This result was published and was also found that 
PHA accumulation started during the late log phase utilising the sugar content as expected and gave a maximum production of $5.85 \mathrm{~g} / \mathrm{L}$ from $8.53 \mathrm{~g} / \mathrm{L}$ of biomass at $72 \mathrm{~h}$ (Geethu et al. 2019).

The $1 \mathrm{~h}$ interval time course growth study of $B$. endophyticus during growth in the bioreactor revealed that the organism directly utilise sucrose and produce PHA during the growth phase (Fig. 4). Biomass was increasing constantly till the nutrients got exhausted till $72 \mathrm{~h}$ and about $1.72 \mathrm{~g} / \mathrm{L}$ of biomass and $0.8 \mathrm{~g} / \mathrm{L}$ of PHA (49.47\% of PHA) was gravimetrically analysed during cultivation and started to reduce after $72 \mathrm{~h}$. The optimal production rate was observed during 68-72 $\mathrm{h}$, indicating that late log phase is the ambient culturing time to extract the polymer before getting utilised by the same strain owing to favourable conditions that may prevail (Fig. 4). The production was found to be reduced as part of the reutilisation by the organism which gave only $38.81 \%$ of PHA. Based on the result depicted in Fig. 4, 70-72 h were considered to be optimum for the maximum production of PHA in B. endophyticus, beyond which the production terminates due to sporulation and cessation of cell growth due to intracellular utilisation of PHA (Valappil et al. 2007; Nair et al. 2014). Application of different statistical design enables proper planning to study the interactions between different parameters. Difference in the PHA production rate is mainly due to the substrate variability and variability of parameter during the production phase (Mohanrasu et al. 2020). The efficient interaction of various parameters with minimal experimental design enables to generate maximal process response.

Based on the result, 70-72 h, late stationary phase was considered to be optimum for the maximum production of PHA in B. endophyticus, beyond which the production terminates due to sporulation and cessation of cell growth, or

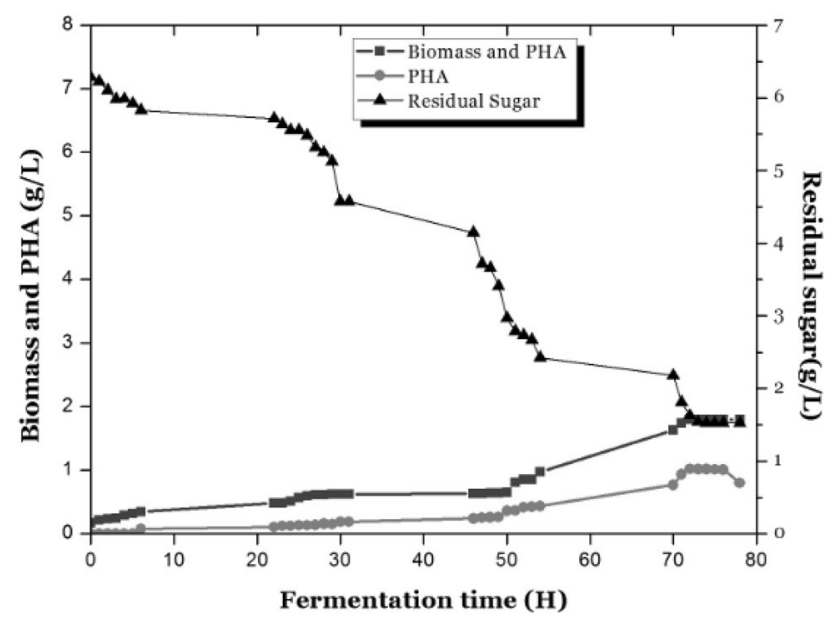

Fig. 4 Growth of B. endophyticus with $1 \mathrm{~L}$ optimal production media in a $3 \mathrm{~L}$ bioreactor PHA due to intracellular utilisation of PHA. PHA seems to get reduced after $76 \mathrm{~h}$ due to reutilisation of the energy storage and hydrolysis reaching stationary phase wich suggests the critical time to harvest the biomass for the optimal gain of PHA. In the low sugar environment provided by the medium during late stationary phase, or in the sugar depleting condition, hydrolysis happens which is mediated by enzymes especially produced by PhaZ gene within the strain (Mansfield et al. 1995; de Andrade Rodrigues et al. 2000). The culture $\mathrm{pH}$ tend to decrease from initial $\mathrm{pH}$ of 7.2-4.8, which inturn effects the cell growth during the stationary stage. But in this condition, the accumulation of PHA can be assumed to be maximum in the existing cells due to the harsh conditions provided in the stationary phase. The main fact is that PHA acts as the carbon source leading to the reduction in the cytoplasmic PHA during the late phases of production itself. The specific optimal production phase of the strain was found to be during late log phase/stationary phase. So any stratergies that can prolong growth phase of the organism enable to increase the PHA yield per biomass.

\section{FTIR and ${ }^{1}$ HNMR analysis of the obtained polymer}

Characterisation of extracted PHA film was confirmed by Fourier transform Infrared (FTIR) and ${ }^{1} \mathrm{H}$ nuclear magnetic resonance (NMR) spectroscopy (Kulkarni et al. 2011). Characterization of PHA obtained from B. endophyticus was represented in Fig. $5 b$ with a characteristic peak $C=O$ stretch at $1726 \mathrm{~cm}^{-1}$ corresponding to the ester group. The strong adsorption band around 1379, 1458, 2929, 1649 and $3749 \mathrm{~cm}^{-1}$ corresponds to $-\mathrm{CH}_{3},-\mathrm{CH}_{2}, \mathrm{CH}, \mathrm{C}-\mathrm{O}$, and $\mathrm{O}-\mathrm{H}$ groups respectively, which was reported to be similar with pure PHB (Fig. 5a).

${ }^{1} \mathrm{H}$ NMR is routinely used as an analytical technique to determine PHA produced. In this study, PHA film obtained after each trial was characterised by ${ }^{1} \mathrm{H}$ NMR. Similar spectral pattern with the standard PHB spectra was obtained (Fig. 6) (Chaijamrus and Udpuay 2008). Characteristic doublet at $1.299 \mathrm{ppm}$ indicated the presence of methyl group was found coupled with single proton. The peak at $2.57 \mathrm{ppm}$, Doublet of quadruplet at corresponding methylene group adjacent to an asymmetric carbon bearing single atom was observed. The methylene group characteristic Multiplet was found precisely on 5.27 was determined from the ${ }^{1} \mathrm{H}$ NMR spectra (Narayanan et al. 2021).

\section{Conclusing remarks}

The process development stratergy for B. endophyticus, an aerobic PHA producer mainly relay on two basic principles like oxygen utilisation behaviour and its capability to cope up with the fermentation parameters economically 
Fig. 5 FTIR spectra of a standard PHB and b PHA extracted from $B$. endophyticus using 4

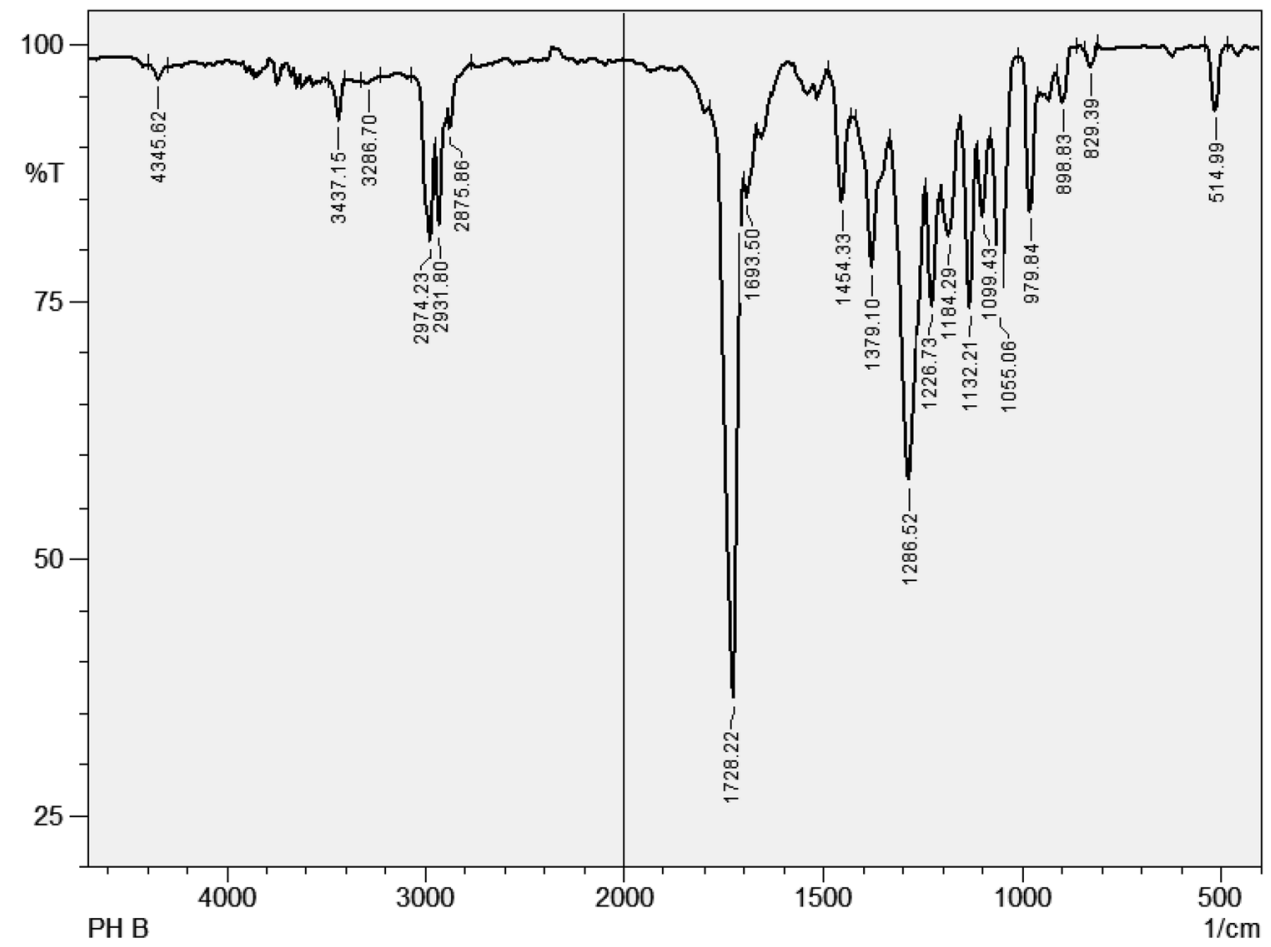

(b)

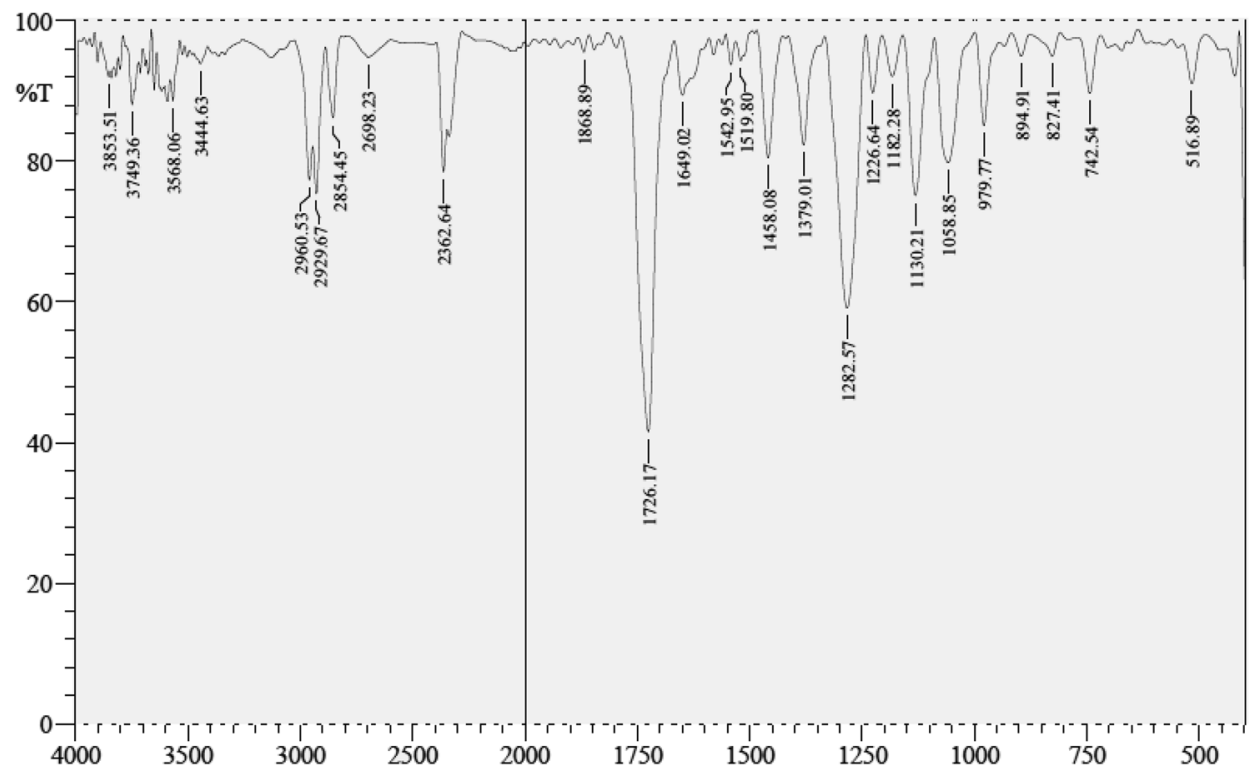

to synthesise PHA. Experimental studies were conducted to identify and optimise factors that significantly influence PHA production in bioreactor. The different parameters influencing the biomass accumulation which in turn increases the PHA synthesis has to be identified and optimized for maximum PHA production. For this, conventional optimization process was carried through bioreactor. PHA producing $B$. endophyticus was found to be an excellent strain to utilize simple sugars like sucrose was an outcome of this study. This study has led to the conclusion in correlating the biomass and PHA production by optimizing two different media conditions so as to increase cell mass during the initial stages and PHA production in the latter stages by altering the media ingredients. The optimization studies showcased the requirement of potassium, and sodium requirement of the strain for growth and maintenance of cell, whereas deficiency of nitrogen source increased PHA production. PHB of $49 \%$ was obtained from the lab scale 


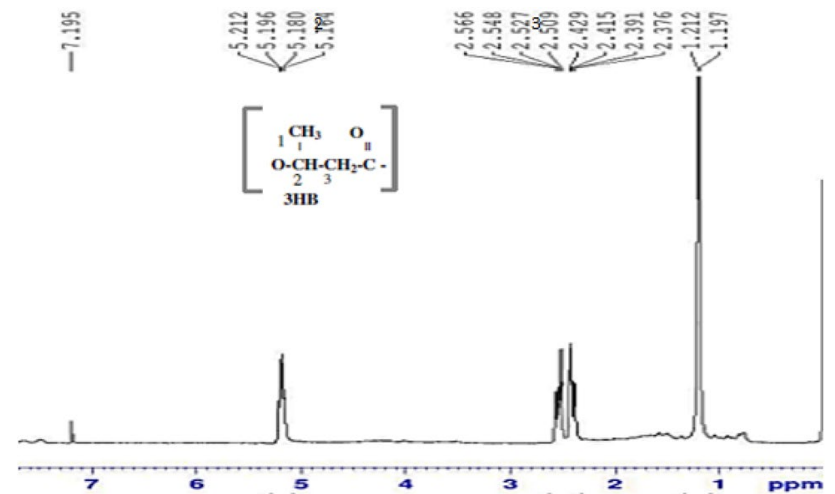

Fig. $6{ }^{1} \mathrm{H}$ NMR spectra of PHA extracted from B. endophyticus using $4 \%$ sucrose as carbon source

bioreactor which was higher than any other PHB producing Bacillus strain utilizing sucrose as sole source of carbon. Further cheap feed stocks rich in sucrose content can be replaced to reduce the overall production rate of PHB in large scale for industrial production.

Acknowledgements The authors are grateful to the Department of Biotechnology (DBT), Government of India, for sponsoring the work (PR 18430/BIC/101/703/2016) and the Department of Biotechnology, Manipal Institute of Technology, Manipal University, India; for providing the facilities to carry out the research work.

Author contributions MG performed the experimental part of this research work as part of her Ph.D. thesis project and dissertation. MSD provided supervision of the research and writing this article (review and editing) and the manuscript. HRC provided the necessary facilities required to initiate the research work.

Funding Open access funding provided by Manipal Academy of Higher Education, Manipal. This study was supported by The Department of Biotechnology (DBT), Government of India, for sponsoring the work (PR 18430/BIC/101/703/2016).

\section{Declarations}

Conflict of interest There is no conflict of interest involved in this research work.

Ethics approval and consent to participate Not applicable.

Consent for publication Not applicable.

Availability of data and materials It will be provided on request and there is no supplementary data provided.

Open Access This article is licensed under a Creative Commons Attribution 4.0 International License, which permits use, sharing, adaptation, distribution and reproduction in any medium or format, as long as you give appropriate credit to the original author(s) and the source, provide a link to the Creative Commons licence, and indicate if changes were made. The images or other third party material in this article are included in the article's Creative Commons licence, unless indicated otherwise in a credit line to the material. If material is not included in the article's Creative Commons licence and your intended use is not permitted by statutory regulation or exceeds the permitted use, you will need to obtain permission directly from the copyright holder. To view a copy of this licence, visit http://creativecommons.org/licenses/by/4.0/.

\section{References}

Akaraonye E, Keshavarz T, Roy I (2010) Production of polyhydroxyalkanoates: the future green materials of choice. J Chem Technol Biotechnol 85(6):732-743. https://doi.org/10.1002/jctb.2392

Amache R, Sukan A, Safari M, Roy I, Keshavarz T (2013) Advances in PHAs production. Chem Eng. https://doi.org/10.3303/CET13 32156

Aramvash A, Shahabi ZA, Aghjeh SD, Ghafari M (2015) Statistical physical and nutrient optimization of bioplastic polyhydroxybutyrate production by Cupriavidus necator. Int J Environ Sci Technol 12:2307-2316. https://doi.org/10.1007/s13762-015-0768-3

Bora L (2013) Polyhydroxybutyrate Accumulation in Bacillusmegaterium and optimization of process parameters using response surface methodology. J Polym Environ 21:415-420. https://doi. org/10.1371/journal.pone.0230443

Chaijamrus S, Udpuay N (2008) Production and characterization of polyhydroxybutyrate from molasses and corn steep liquor produced by Bacillus megaterium ATCC 6748. Agric Eng Int CIGR J. https://cigrjournal.org/index.php/Ejounral/article/view/1216

Chen G-Q, Jiang X-R (2018) Engineering microorganisms for improving polyhydroxyalkanoate biosynthesis. Curr Opin Biotechnol 53:20-25. https://doi.org/10.1016/j.copbio.2017.10.008

Rodrigues MF, Valentin HE, Berger PA, Tran M, Asrar J, Gruys KJ, Steinbüchel A (2000) Polyhydroxyalkanoate accumulation in Burkholderia sp.: a molecular approach to elucidate the genes involved in the formation of two homopolymers consisting of short-chain-length 3-hydroxyalkanoic acids. Appl Microbiol Biotech 53:453-460. https://sfamjournals.onlinelibrary.wiley. com/doi/pdfdirect/10.1111/jam.13469

Md Din MF, Ponraj M, Van Loosdrecht M, Ujang Z, Chelliapan S, Zambare V (2014) Utilization of palm oil mill effluent for polyhydroxyalkanoate production and nutrient removal using statistical design. Int J Environ Sci Technol 11:671-684. https://doi.org/10. 1007/s13762-013-0253-9

Geethu M, Vrundha R, Raja S, Raghu Chandrashekar H, Divyashree MS (2019) Improvement of the production and characterisation of polyhydroxyalkanoate by Bacillus endophyticus using inexpensive carbon feedstock. J Polym Environ 27:917-928. https://link.sprin ger.com/article/10.1007/s10924-019-01397-z

Kaur G, Roy I (2015) Strategies for large-scale production of polyhydroxyalkanoates. Chem Biochem Eng Q 29:157-172. https://doi. org/10.15255/CABEQ.2014.2255

Kulkarni SO et al (2011) Characterisation of copolymer, poly (hydroxybutyrate-co-hydroxyvalerate) (PHB-co-PHV) produced by Halomonas campisalis (MCM B-1027), its biodegradability and potential application. Bioresour Technol 102:6625-6628. https://doi.org/10.1016/j.biortech.2011.03.054

Lakshman K, Shamala TR (2006) Extraction of polyhydroxyalkanoate from Sinorhizobium meliloti cells using Microbispora sp. culture and its enzymes. Enzyme Microb Technol 39:1471-1475. https:// doi.org/10.1016/j.enzmictec.2006.03.037

Mansfield DA, Anderson AJ, Naylor LA (1995) Regulation of PHB metabolism in Alcaligenes eutrophus. Can J Microbiol 41:44-49. https://doi.org/10.1139/m95-166

Miller GL (1959) Use of dinitrosalicylic acid reagent for determination of reducing sugar. Anal Chem 31:426-428 
Mohammed S, Behera HT, Dekebo A, Ray L (2019) Optimization of the culture conditions for production of Polyhydroxyalkanoate and its characterization from a new Bacillus cereus $\mathrm{sp}$. BNPI-92 strain, isolated from plastic waste dumping yard. Int J Biol Macromol. https://doi.org/10.1016/j.ijbiomac.2019.11.138

Mohanrasu K et al (2020) Optimization of media components and culture conditions for polyhydroxyalkanoates production by Bacillus megaterium. Fuel 271:117522

Nair AM, Annamalai K, Kannan SK, Kuppusamy S (2014) Characterization of polyhydroxyalkanoates produced by Bacillus subtilis isolated from soil samples. Malaya J Biosci 1:8-12

Narayanan M et al (2021) Optimization and production of polyhydroxybutyrate from sludge by Bacillus cereus categorized through FT-IR and NMR analyses. J Environ Chem Eng 9:104908. https:// doi.org/10.1016/j.jece.2020.104908

Pijuan M, Casas C, Baeza JA (2009) Polyhydroxyalkanoate synthesis using different carbon sources by two enhanced biological phosphorus removal microbial communities. Process Biochem 44(1):97-105. https://doi.org/10.1016/j.procbio.2008.09.017

Pillai AB, Kumar AJ, Thulasi K, Kumarapillai H (2017) Evaluation of short-chain-length polyhydroxyalkanoate accumulation in Bacillus aryabhattai. Braz J Microbiol 48:451-460. https://doi.org/10. 1016/j.bjm.2017.01.005

Prados E, Maicas S (2016) Bacterial production of hydroxyalkanoates (PHA). Univ J Microbiol Res 4:23-30. https://doi.org/10.13189/ ujmr.2016.040104
Russell A (2003) Lethal effects of heat on bacterial physiology and structure. Sci Prog 86 (1-2):115-137. https://doi.org/10.3184/ 003685003783238699

Slepecky RA, Law JH (1960) A rapid spectrophotometric assay of alpha, beta-unsaturated acids and beta-hydroxy acids. Anal Chem 32 (12):1697-1699. https://doi.org/10.1021/ac60168a046

Tripathi AD, Srivastava SK, Singh RP (2013) Statistical optimization of physical process variables for bio-plastic (PHB) production by Alcaligenes sp. Biomass Bioenerg 55:243-250. https://agris.fao. org/agris-search/search.do?recordID $=$ US201500155357

Valappil SP, Boccaccini AR, Bucke C, Roy I (2007) Polyhydroxyalkanoates in Gram-positive bacteria: insights from the genera Bacillus and Streptomyces. Anton Leeuw 91:1-17. https://doi. org/10.1007/s10482-006-9095-5

Wang J, Bakken L (1998) Screening of soil bacteria for poly- $\beta$ hydroxybutyric acid production and its role in the survival of starvation. Microb Ecol 35:94-101. https://doi.org/10.1007/s0024 89900063

Yao Z, Davis RM, Kishony R, Kahne D, Ruiz N (2012) Regulation of cell size in response to nutrient availability by fatty acid biosynthesis in Escherichia coli. PNAS 109 (38):E2561-E2568. https:// doi.org/10.1073/pnas.1209742109

Publisher's Note Springer Nature remains neutral with regard to jurisdictional claims in published maps and institutional affiliations. 